Original Research Article

\title{
Cost minimization analysis of generic and innovator formulations of antihypertensive drugs
}

\author{
Vishalkumar K. Vadgama ${ }^{1}$, Vishal L. Gaekwad ${ }^{2} *$
}

${ }^{1}$ Department of Pharmacology, Government Medical College, Bhavnagar, Gujarat, India ${ }^{2}$ Department of Pharmacology, Baroda Medical College, Baroda, Gujarat, India

Received: 01 November 2019

Revised: 16 November 2019

Accepted: 18 November 2019

\section{*Correspondence to:}

Dr. Vishal L. Gaekwad, Email: vishalgaekwad305@ gmail.com

Copyright: (C) the author(s), publisher and licensee Medip Academy. This is an openaccess article distributed under the terms of the Creative Commons Attribution NonCommercial License, which permits unrestricted noncommercial use, distribution, and reproduction in any medium, provided the original work is properly cited.

\begin{abstract}
Background: Hypertension, a chronic condition requiring lifelong care, affects approximately $25.3 \%$ Indian population. Average annual hypertension management cost which also includes medication cost varies from Rs. 4042 to 7621 , amounting up to $40 \%$ of total household income of few families. Selection of a different brand or generic formulation may have an immense impact on total expenditure for treatment of hypertension. Present study aims at determining cost variability and cost analysis of various single drug antihypertensive formulations available in Indian market.

Methods: One most prescribed drug, each from Joint National Committee recommended antihypertensive- thiazide diuretics, calcium channel blockers, angiotensin converting enzyme inhibitors, angiotensin-receptor blockers and $\beta$ blockers were selected for cost analysis. Cheapest, costliest and median priced formulations were searched for individual drugs and were compared to the price of their generic counterparts.

Results: Generic formulations of hydrochlorothiazide, amlodipine, enalapril, losartan and atenolol were cheaper even than their respective cheapest innovator formulations. Costliest innovator formulation of amlodipine was 1750\% expensive than generic one. Costliest counterparts of generic formulations were many folds overpriced. Similarly, innovator formulation of losartan was up to $953.89 \%$ costly than generic one. Innovator formulations of hydrochlorothiazide were the least costly than its generic counterpart, yet being at least $150 \%$ more expensive. Also, there exists considerable broad range of price among similar innovator formulations.

Conclusions: By prescribing generic antihypertensive drug, we can reduce treatment expenditure by many folds. Same feat can be marginally achieved by using lower cost innovator formulations.
\end{abstract}

Keywords: Cost minimization, Antihypertensive, Generic, Innovator, Hypertension

\section{INTRODUCTION}

Hypertension or high blood pressure, is when force of blood flowing through one's blood vessels is consistently too high. According to WHO, hypertension is diagnosed if, when it is measured on two different days, the systolic blood pressure readings on both days is $\geq 140 \mathrm{mmHg}$ and/or the diastolic blood pressure readings on both days is $\geq 90 \mathrm{mmHg}$. ${ }^{1}$ Hypertension is classified in two different types which are essential hypertension and secondary hypertension. Essential hypertension, most commonly occurring of two, has no known cause and can be associated with a multitude of pathophysiological factors. Hyperactive sympathetic nervous system, certain dietary habits like high sodium intake, long standing uncontrolled diabetes mellitus, lack of regular physical exercise leading to obesity are few probable causes of essential hypertension. ${ }^{2}$ While, separate pathophysiological conditions like renal disease, primary hyperaldosteronism, and obstructive sleep apnea often results in secondary hypertension. ${ }^{3}$ Overall, hypertension occurs in an estimated 26 percent of world's population 
(972 million people), and the incidence is expected to rise to 29 percent by 2025 , driven largely by low and middle income countries. ${ }^{4}$ In India, fourth district level household survey, reported higher prevalence of hypertension in men $(27.4 \%)$ than women $(20.0 \%)$ at 25.3 percent (age $>18$ years). ${ }^{5}$

Hypertension, a chronic disorder requiring lifelong treatment in majority of patients. In this scenario, treatment of hypertension would consume significant fraction of income of a household. Globally, monthly cost for hypertension treatment is around $\$ 22 .^{6}$ While, an Indian study reported that, Rs. 7154 was the average total annual cost of hypertension and related disorders. For government and private hospital facilities, the average annual out of pocket expenditure was Rs. 4042 and Rs. 7621 respectively. Fifteen percent of households were catastrophically spending 40 percent of household income in management of hypertension. ${ }^{7}$ This scenario warrants need of cost reduction for the treatment of hypertension.

Hypertension's economic costs include direct medical costs as well as indirect costs such as loss of productivity. Direct medical costs are the costs of medical products and services used for the prevention, diagnosis and treatment of a disease and its complications. These costs include hospitalization expenses, emergency room visits, doctor visits, laboratory and imaging tests, home health care, and prescription drugs. Among this, cost of prescription drugs, a monthly recurring expense, often for a lifetime is an important contributing factor in determining total expenditure behind treatment of hypertension. Cost of medicines varies among various company brands, generic formulations as well as government supplied or subsidized drugs. Generic formulations; defined as a medication created to be the same as an already marketed brand-name drug in dosage form, safety, strength, route of administration, quality, performance characteristics, and intended use; are perceived as cheaper formulations. ${ }^{8}$ But, cost comparison data of generic formulations to their innovator counterparts is not readily available, which may lead to selection of a particular brand or supplied drug over generic formulation. This decision has potential to immensely impact total expenditure on treatment of hypertension. Therefore, to aid treating physicians and patients in properly selecting generic or innovator formulations, present study was directed to carry out cost comparison by determining cost variability and doing cost analysis of various single drug antihypertensive formulations available in Indian market.

\section{METHODS}

Generic medicines are well-tested pharmaceutical products of proven high quality. They are strictly regulated by the competent national and only through a comprehensive quality control process; they are given authorization. This procedure ensures that the generic medicines available in the market are sufficiently safe and effective. ${ }^{9}$ Hence, generic drugs and innovator drugs are considered as of similar efficacy and only their direct to patient cost were taken in to consideration for analysis in present study.

Prices of generic formulations of selected medicines were obtained from local generic medicine drug dispensing stores of different district of Gujarat. While prices of innovator formulations of selected medicines were obtained from CIMS and database. ${ }^{10,11}$

Thiazide diuretics, calcium channel blockers, angiotensin converting enzyme inhibitors and angiotensin-receptor blockers are recommended first line drugs for the treatment of various types of hypertension by Joint National Committee-8 (JNC-8). ${ }^{12}$ In India, among thiazide diuretics, calcium channel blockers, angiotensin converting enzyme inhibitors and angiotensin-receptor blockers; hydrochlorothiazide, amlodipine, enalapril and losartan are most prescribed drugs among respective groups and hence their single drug oral formulations were selected for cost analysis in present study. ${ }^{13,14} \beta$ blockers, which were considered as first line antihypertensive drug by JNC 7, and still one of the most commonly prescribed antihypertensive drugs in India were also included in the present study. Atenolol was selected from the $\beta$ blockers group for cost comparison and analysis.

Present study was carried out at pharmacology departments of government medical college, Bhavnagar, Gujarat and medical college, Baroda, Gujarat, during September, 2019 to November, 2019.

Drugs' prices were analyzed and cheapest and costliest and median priced formulations were searched for individual drugs and were compared to the price of their generic counterparts. Data is presented as absolute numbers as well as percentage cost difference between individual drugs formulations. They were also presented with their cost difference to median priced drug formulation of respective drugs.

Microsoft Excel (version 15.0) was used for data management and calculation.

\section{RESULTS}

For hydrochlorothiazide, cost of generic $12.5 \mathrm{mg}$ and 25 mg single drug oral formulations were Rs. 4 and Rs. 8, respectively. Cost of their innovator counterparts varied from Rs. 6.75-10.3 with many formulation nearing price of Rs. 9.17 for $12.5 \mathrm{mg}$ dose, while for $25 \mathrm{mg}$ dose cost varied from Rs. 12-18 with many falling near price of Rs. 17.14. These findings suggests that cost of innovator medicine are overpriced at least $168.75 \%$ to generic formulation and price goes all the way higher up to $257.5 \%$ for $12.5 \mathrm{mg}$ dose. Same with $25 \mathrm{mg}$ dose, cost of innovator formulations was higher from 150-231.25\% than their generic counterparts. Even among innovator 
formulations price varied from 1.53 to 1.54 fold between cheapest and costliest formulations (Table 1, Figure 1).

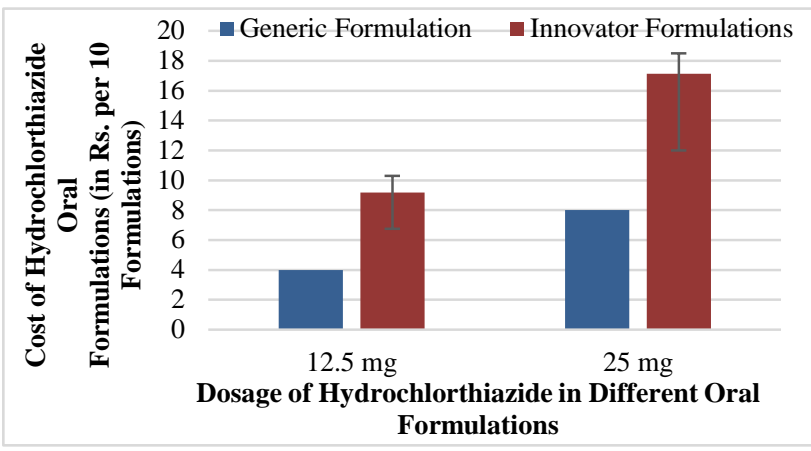

Figure 1: Price variability of hydrochlorothiazide for various therapeutically used doses and their individual comparison with their generic counter parts (cost in Rs. per 10 formulations).

The price of generic $2.5 \mathrm{mg}, 5 \mathrm{mg}$ and $10 \mathrm{mg}$ of single oral drug formulations of amlodipine was Rs. 4, Rs. 4 Rs. 6 , respectively. The cost of their innovator counterparts ranged from Rs. 6.5-27.7 with many formulations close to Rs. 16.38 for $2.5 \mathrm{mg}$ dose, while the price of $5 \mathrm{mg}$ dose varied from Rs. 9.71-70 with many falling close to Rs. 25.5, while the cost of $10 \mathrm{mg}$ dose varied from Rs. 16-79.97 with many falling close to Rs. 50.04. This findings suggest that the value of innovator formulation is at least $162.5 \%$ overpriced and that the price may rise up to $693.75 \%$ for dose of $2.5 \mathrm{mg}$. Same with $5 \mathrm{mg}$ dose, cost of innovator formulations were higher from 242.75$1750 \%$ than their generic counterparts. Price of innovator formulations were from 200-999.62\% higher as compared to $10 \mathrm{mg}$ generic formulations. The most expensive formulations for $2.5 \mathrm{mg}, 5 \mathrm{mg}$ and $10 \mathrm{mg}$ are up to $4.27,7.21$ and 5 fold higher than their respectively cheapest formulations among innovative formulations (Table 1, Figure 2).

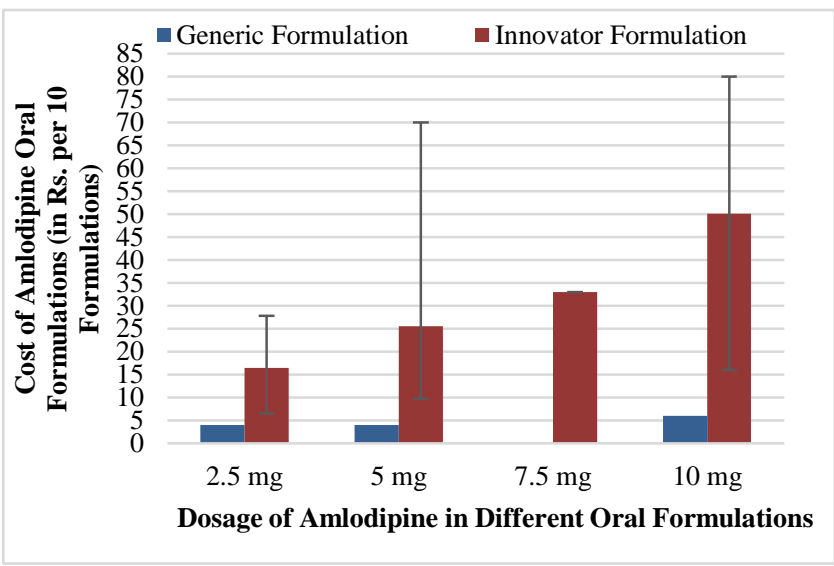

Figure 2: Price variability of amlodipine for various therapeutically used doses and their individual comparison with their generic counter parts (cost in Rs. per 10 formulations).
For enalapril, cost of generic $5 \mathrm{mg}$ and $10 \mathrm{mg}$ single drug oral formulations were Rs. 4 and Rs. 12, respectively. Cost of their innovator counterparts varied from Rs. 6.2533.71; with many formulation nearing price of Rs. 29.15 for $5 \mathrm{mg}$ dose, while for $10 \mathrm{mg}$ dose, cost varied from Rs. 27.75-66.4 with many falling near price of Rs. 37.75. Such results suggest that innovator formulations' prices are overpriced for a generic formulation at least $156.25 \%$ and price may further increase by up to $842.75 \%$ for a dosage of $5 \mathrm{mg}$. Same with $10 \mathrm{mg}$ dose, cost of innovator formulations were higher from 231.25-553.33\% than their generic counterparts. The cost of the most expensive $2.5 \mathrm{mg}, 5 \mathrm{mg}$ and $10 \mathrm{mg}$ formulations was even higher up to $1.95,5.39$ and 2,39 fold than those of their respective cheapest innovative formulations (Table 1, Figure 3).

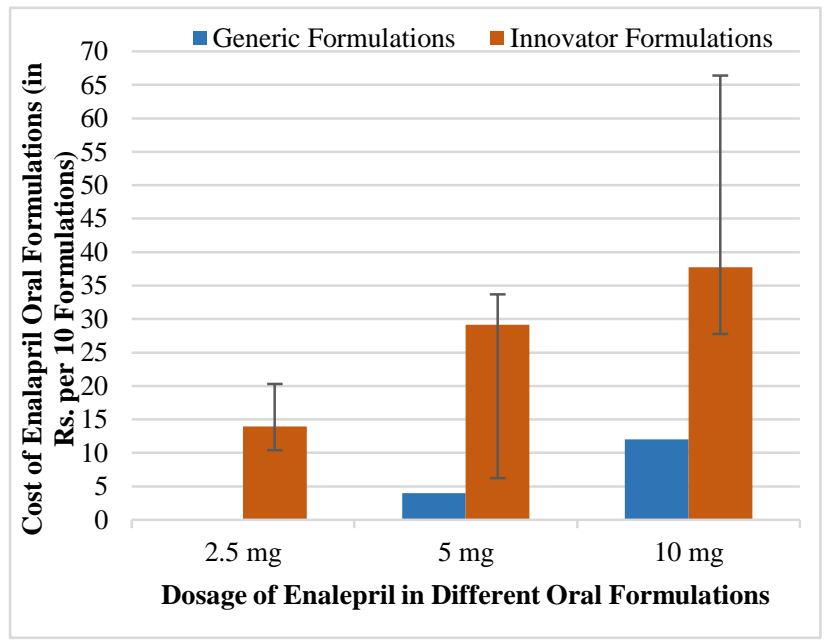

Figure 3: Price variability of enalapril for various therapeutically used doses and their individual comparison with their generic counter parts (cost in Rs. per 10 formulations).

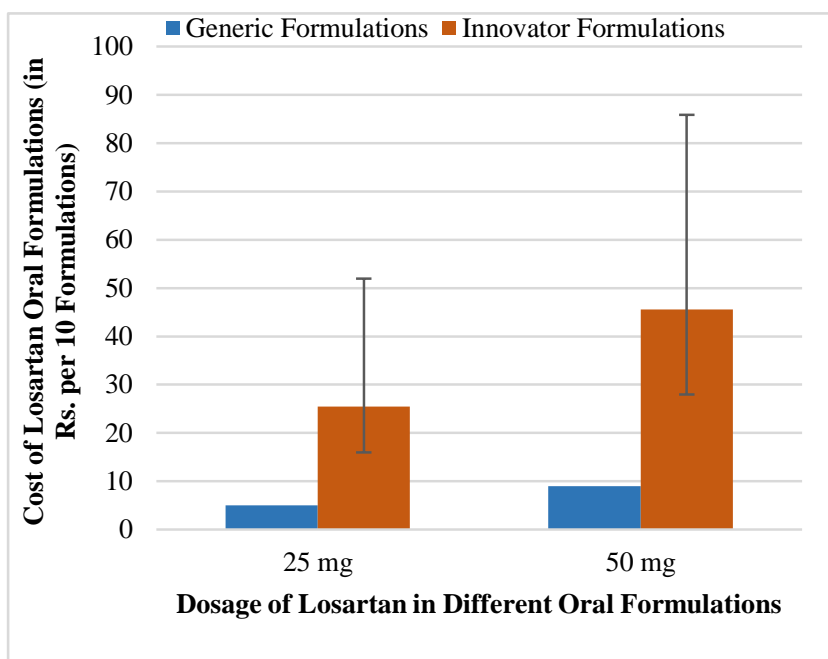

Figure 4: Price variability of losartan for various therapeutically used doses and their individual comparison with their generic counter parts (cost in Rs. per 10 formulations). 
Table 1: Price variability of hydrochlorothiazide, amlodipine, enalapril, losartan and atenolol for various therapeutically used doses and their individual comparison with their generic counter parts (cost in Rs. per 10 formulations).

\begin{tabular}{|c|c|c|c|c|c|}
\hline \multirow[t]{2}{*}{$\begin{array}{l}\text { Name of drug and dosage of } \\
\text { formulations }\end{array}$} & \multirow{2}{*}{$\begin{array}{l}\text { Cost of } \\
\text { generic } \\
\text { formulation }\end{array}$} & $\begin{array}{l}\text { Cheapest } \\
\text { innovator } \\
\text { formulation }\end{array}$ & $\begin{array}{l}\text { Median cost } \\
\text { innovator } \\
\text { formulation }\end{array}$ & $\begin{array}{l}\text { Costliest } \\
\text { innovator } \\
\text { formulation }\end{array}$ & \multirow{2}{*}{$\begin{array}{l}\text { Fold } \\
\text { increase } \\
\text { in cost }\end{array}$} \\
\hline & & $\mathbf{N}(\%)$ & $\mathbf{N}(\%)$ & $\mathbf{N}(\%)$ & \\
\hline Hydrochlorothiazide $2.5 \mathrm{mg}$ & 4 & $6.75(168.75)^{*}$ & $9.175(229.37)^{*}$ & $10.3(257.5)^{*}$ & 1.53 \\
\hline Hydrochlorothiazide 25 mg & 8 & $12(150)^{*}$ & $17.14(214.25)^{*}$ & $18.5(231.25)^{*}$ & 1.54 \\
\hline Amlodipine 2.5 mg & 4 & $6.5(162.5)^{*}$ & $16.38(409.5)^{*}$ & $27.75(693.75)^{*}$ & 4.27 \\
\hline Amlodipine 5 mg & 4 & $9.71(242.75)^{*}$ & $25.5(637.5)^{*}$ & $70(1750)^{*}$ & 7.21 \\
\hline Amlodipine $7.5 \mathrm{mg}$ & N.A. & 33 & 33 & 33 & - \\
\hline Amlodipine 10 mg & 6 & $16(200)^{*}$ & $50.04(625.56)^{*}$ & $79.97(999.62)^{*}$ & 5 \\
\hline Enalapril $2.5 \mathrm{mg}$ & N.A. & 10.4 & 13.95 & 20.27 & 1.95 \\
\hline Enalapril 5 mg & 4 & $6.25(156.25)^{*}$ & $29.15(728.75)^{*}$ & $33.71(842.75)^{*}$ & 5.39 \\
\hline Enalapril $10 \mathrm{mg}$ & 12 & $27.75(231.25)^{*}$ & $37.75(314.58)^{*}$ & $66.4(553.33)^{*}$ & 2.39 \\
\hline Losartan 25 mg & 5 & $15.95(319)^{*}$ & $25.5(510)^{*}$ & $52(1040)^{*}$ & 3.26 \\
\hline Losartan 50 mg & 9 & $28(311.11)^{*}$ & $45.55(506.11)^{*}$ & $85.85(953.89)^{*}$ & 3.07 \\
\hline Atenolol $12.5 \mathrm{mg}$ & N.A. & 2 & 4.46 & 19.6 & 9.8 \\
\hline Atenolol 25 mg & 2.86 & $6.39(223.43)^{*}$ & $16(559.44)^{*}$ & $24.22(846.85)^{*}$ & 3.79 \\
\hline Atenolol $50 \mathrm{mg}$ & 3.57 & $6.77(189.63)^{*}$ & $17.64(494.12)^{*}$ & $23.07(646.22)^{*}$ & 3.41 \\
\hline Atenolol 100 mg & 7.14 & $15.64(219.05)^{*}$ & $32.85(460.08)^{*}$ & $40.88(572.55)^{*}$ & 2.61 \\
\hline
\end{tabular}

$\$=$ Fold increase in cost between cheapest to costliest innovator formulations; *=Price difference (in percentage) between individual innovator formulation to its generic counterpart; N.A.= Generic formulation not available.

For losartan, cost of generic $25 \mathrm{mg}$ and $50 \mathrm{mg}$ single drug oral formulations were Rs. 5 and Rs. 9, respectively. Cost of their innovator counterparts varied from Rs. 15.95 to Rs.52; with many formulation nearing price of Rs. 25.5 for $25 \mathrm{mg}$ dose, while for $50 \mathrm{mg}$ dose, cost varied from Rs. 28-85.85; with many falling near price of Rs. 45.55 . These findings suggests that cost of innovator medicine are overpriced at least $319 \%$ to generic formulation and price goes all the way higher up to $1040 \%$ for $25 \mathrm{mg}$ dose. Same with $50 \mathrm{mg}$ dose, cost of innovator formulations were higher from 311.11 to $953.89 \%$ than their generic counterparts. Even among innovator formulations, costliest formulations' price for $25 \mathrm{mg}$ and $50 \mathrm{mg}$ were up to 3.26 and 3.07 fold higher than their respective cheapest innovator formulations (Table 1, Figure 4).

For atenolol, cost of generic $25 \mathrm{mg}, 50 \mathrm{mg}$ and $100 \mathrm{mg}$ single drug oral formulations were Rs. 2.86, Rs. 3.57, Rs. 7.14, respectively. Cost of their innovator counterparts varied from Rs. 6.39 to Rs. 24.22 with many formulation nearing price of Rs. 16 for $25 \mathrm{mg}$ dose, while for $50 \mathrm{mg}$ dose cost varied from Rs. 6.77-23.07 with many falling near price of Rs. 17.64; for $100 \mathrm{mg}$ dose cost varied from Rs. 15.64 to Rs. 40.88 with many falling near price of Rs. 32.85. These findings suggests that cost of innovator medicine are overpriced at least $223.43 \%$ to generic formulation and price goes all the way higher up to $846.85 \%$ for $25 \mathrm{mg}$ dose. Same with $50 \mathrm{mg}$ dose, cost of innovator formulations were higher from 189.63-646.22\% than their generic counterparts. Price of innovator formulations were from 219.05-572.55\% higher as compared to $100 \mathrm{mg}$ generic formulations. Even among innovator formulations, costliest formulations' price for $12.5 \mathrm{mg}, 25 \mathrm{mg}, 50 \mathrm{mg}$ and $100 \mathrm{mg}$ were up to $9.8,3.79$, 3.41 and 2.61 fold higher than their respective cheapest innovator formulations (Table 1, Figure 5).

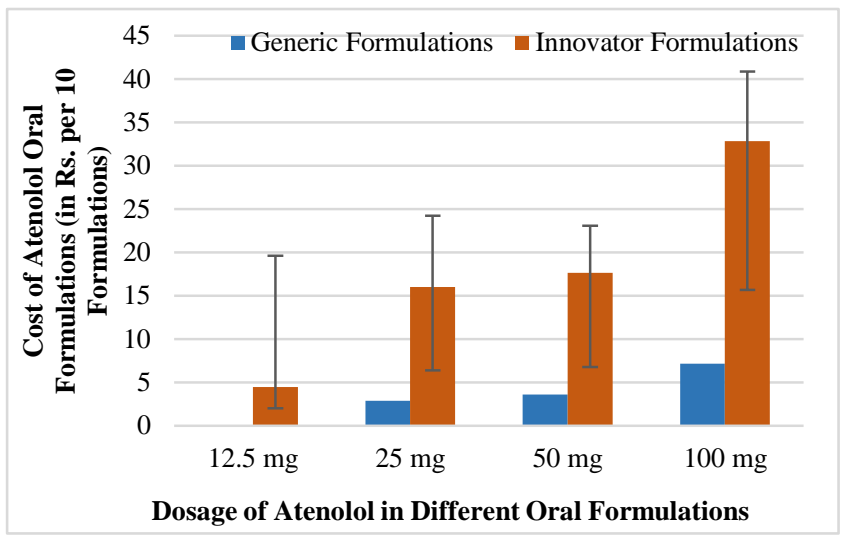

Figure 5: Price variability of atenolol for various therapeutically used doses and their individual comparison with their generic counter parts (cost in Rs. per 10 formulations).

\section{DISCUSSION}

Treatment of a life style disorder i.e., hypertension is a costly affair as it acquires regular recurring costs often for lifelong duration. It is necessary to encourage complete adherence to drug therapy for optimal control of hypertension. Yet, in real world scenario, compliance to 
the treatment of hypertension is low. There are multiple reasons for non-adherence, but relative high cost of medicines, is one of few pertinent causes for nonadherence to treatment in India. ${ }^{15}$ As a result, if patient is opted for the drug which is of higher cost than he can afford, his adherence to the treatment gets affected. ${ }^{16}$ Even if the patient tries to cope with cost of medicine, his family income may get blunted resulting in poorer household conditions and lesser expenditure on essential modalities like nutrition and education. A study reported that fifteen percent households were incurring catastrophic expenditure at highest threshold of $40 \%$ of their household income, leading to impoverishment of $34.2 \%$ households. $^{7}$ Hence, price of medicine remains one of the important factor which can be minimized to provide affordable treatment options to patient.

Hence, selection of proper drug formulations becomes an important aspect in improving adherence to treatment protocols for chronic lifestyle disorders. Cumulative cost imparted by costliest formulation as compared to cheapest formulation or generic formulation may be many fold in long run. If, instead of generic formulation of hydrochlorothiazide, its innovator formulations are prescribed, cost of daily therapy may increase anywhere between 1.69 to 2.57 fold (168.75-257.5\% difference between costs). Most commonly utilized maintenance doses of amlodipine are $5 \mathrm{mg}$ and $10 \mathrm{mg}$ OD. If innovator formulations of amlodipine are selected, they will increase cost burden for medicines up to 2.42 to staggering 17 fold per day (242.75-1750\% difference between cost) and 2 to 10 fold (200-999.62\% difference between costs) in case of $5 \mathrm{mg}$ and $10 \mathrm{mg}$ OD therapy, respectively. Similarly, if innovator formulations of enalapril are selected over generic, patient will be spending 1.5 to 8.4 fold higher amount for $5 \mathrm{mg}$ dose (156.25-842.75\% difference between cost of formulations) and 2.3 to 5.53 fold higher amount, daily for $10 \mathrm{mg}$ dose (formulation cost difference of 231.25$553.33 \%$ ). These situation becomes dreadful in case of losartan if patient is prescribed with costliest innovator formulation for $25 \mathrm{mg}$ daily dose; expenditure increases to 10 fold over generic one as cost of this innovator formulation is $1040 \%$ high than its generic counterpart. Similar higher expenditure can be anticipated in case of $50 \mathrm{mg}$ innovator formulations. Coming to one of the most prescribed antihypertensive agent atenolol, its generic formulations are up to 8.46, 6.46 and 5.72 fold cheaper than their counterpart innovator formulations of $25 \mathrm{mg}$, $50 \mathrm{mg}$ and $100 \mathrm{mg}$, respectively.

Dilemma between selecting generic formulations and innovator formulations are perceived by many physicians and patients. In this scenario, even if one prefers innovator formulations and selects the cheapest available innovator formulation, one can save substantially. Like cost of cheapest innovator formulations were up to 1.5 , $7.21,5.39,3.26$ and 3.41 fold cheaper than their costliest counterparts in case of commonly prescribed doses of hydrochlorothiazide, amlodipine, enalapril, losartan and atenolol.

Awareness regarding availability of various generic and innovator formulations or cheaper and costly ones; helps in proper selection of formulations for each patient. This information will also help patient in selecting a formulation according his willingness to spend and affordability. This in turn, will improve compliance and adherence to the treatment goals, leading to effective management of hypertension.

\section{CONCLUSION}

Available data shows price of generic formulations are found to be less than all of their innovator counterpart formulations for selected antihypertensive drugs. Cost of costliest of innovator formulations is found to be many fold high in many antihypertensive drugs than their cheapest counterparts.

\section{Funding: No funding sources \\ Conflict of interest: None declared \\ Ethical approval: Not required}

\section{REFERENCES}

1. Hypertension. Available at: https://www.who.int/ news-room/fact-sheets/detail/hypertension. Accessed on 1 October 2019.

2. Oparil S, Zaman M, Calhoun D. Pathogenesis of Hypertension. Ann Intern Med. 2003;139:761-76.

3. Puar T, Mok Y, Debajyoti R, Khoo J, How C, Ng A. Secondary hypertension in adults. Singapore Med J. 2016;57:228-32.

4. Kearney P, Whelton M, Reynolds K, Muntner P, Whelton P, He J. Global burden of hypertension: analysis of worldwide data. Lancet. 2005;365:21723.

5. Gupta R, Gaur K, Ram C. Emerging trends in hypertension epidemiology in India. $\mathrm{J}$ Hum Hypertens. 2019;33:575-87.

6. Gheorghe A, Griffiths U, Murphy A, Legido-Quigley H, Lamptey P, Perel P. The economic burden of cardiovascular disease and hypertension in low- and middle-income countries: a systematic review. BMC Public Health. 2018; 18:975.

7. Thakare B, Adhav A, Kadam S. Economic burden of hypertension care on households of Malwani slum of Mumbai: a cross-sectional study. Int J Res Med Sci. 2015;6:2376-81.

8. Generic Drugs: Questions and Answers. Available at: http://www.fda.gov/drugs/questions-answers/genericdrugs-questions-answers. Accessed on 1 October 2019.

9. Baumgärtel C. Myths, questions, facts about generic drugs in the EU. Generics Biosimilars Initiative J. 2012;1:34-8.

10. CIMS Medica. In: 146th ed. Bengaluru: CIMS Medica India Pvt Ltd; 121-147. 
11. IDR Triple I Compendium. Bengaluru: CIMS Medica India Pvt Ltd; 2018: 37-53.

12. James P, Oparil S, Carter B, Cushman W, DennisonHimmelfarb C, Handler J, et al. Evidence-Based Guideline for the Management of High Blood Pressure in Adults: Report From the Panel Members Appointed to the Eighth Joint National Committee (JNC 8). JAMA. 2014;311:507-20.

13. Solanki K, Mistry R, Singh A, Jadav S, Patel N, Trivedi H. Drug utilization study of anti-hypertensive drugs and their adverse effects in patients of a tertiary care hospital. J Clin Exp Res. 2013;1:58-67.

14. Rachana P, Anuradha H, Shivamurthy M. Antihypertensive prescribing patterns and cost analysis for primary hypertension: a retrospective study. JCDR. 2014;8(9):19-22.

15. Gupta R, Yusuf S. Towards better hypertension management in India. Indian $\mathrm{J}$ Med Res. 2014;139:657-60.

16. Jimmy B, Jose J. Patient medication adherence: measures in daily practice. Oman Med J. 2011;26:155-9.

Cite this article as: Vadgama VK, Gaekwad VL. Cost minimization analysis of generic and innovator formulations of antihypertensive drugs. Int J Basic Clin Pharmacol 2019;8:2625-30. 